ever, which find a satisfactory explanation only if it is assumed that an epoxide is formed in the initial phase.

It is known that some olefins on oxidation by aqueous chromic acid in sulphuric acid give not only the expected fission products but also acids which contain the same number of carbon atoms as the original olefin. Thus, dineopentyl ethylene (VII) gives a good yield of dineopentyl acetic acid (VIII); $2: 4: 4$-trimethyl pentene-1 (IX) gives the fission product neopentyl methyl ketone as well as $2: 4: 4$ trimethyl pentanoic acid (X); $2: 4: 4$-trimethyl pentene-2 (XI) yields acetone and trimethyl acetic acid as well as $2: 2: 3: 3$-tetramethyl butanoic acid (XII). In all these examples it is known that the epoxide isomerizes to the aldehyde corresponding to the acid isolated; there is good qualitative agreement between the extent of this isomerization and the yield of the acid in the oxidation.

An alternative hypothesis based on the assumption that a glycol is the initial product of the oxidation is less satisfactory; the rate of oxidation of glycols is in general greater than their rate of isomerization.

We acknowledge substantial support from the Research Group of the Institute of Petroleum, assistance from the Research Fund of the University of London and a maintenance grant from the Department of Scientific and Industrial Research.

W. J. HICKINBOTTOM

D. G. M. WooD

Queen Mary College,

University of London, E.1. March 5.

${ }^{1}$ Byers and Hickinbottom, J. Chem. Soc., 1334 (1948).

${ }^{2}$ Norris, Thomas and Brown, Ber., 43, 2954 (1910).

${ }^{3}$ Behr, Ber., 5, 277 (1872).

- Biltz, Ann., 296. 23 (1897).

'Bockemiiller and Jansen, Ann., 542, 166 (1939).

'Fieser and Fieser, "Natural Products related to Phenanthrene", 229 $(1949)$.

\section{Solubility of Ethylenediamine D-Tartrate in Water}

IN a recent paper', A. C. Walker has given tables and curves for the solubility-temperature relationship in the system ethylenediamine D-tartrate (anhyd.)ethylenediamine D-tartrate monohydrate-water. Dr. Walker shows that the salt decomposes slowly in solution, and the consequent change of composition of the solute during the time taken by the solubility determinations introduces some uncertainty in the results. Usually, when preparing a solubility curve, a considerable time must be allowed, at each observed temperature, for equilibrium between solution and solute to be attained. The change of composition of the solute during the experiments is probably responsible for the difference in level, of the order of $1^{\circ} \mathrm{C}$., in two of the published curves.

In our work on growing large crystals of watersoluble substances, we have for some time been using a method for the direct estimation of the saturation temperature of solutions. The solution is circulated through a cell in which it is continuously brought into equilibrium with the solid phase being studied. Any departure from equilibrium in the cell is detected by observing a simple optical effect near the surface of a piece of crystal. The bulk of the solution is merely required to be uniform and free from solid; it is not necessary that it should at any stage be exactly at its saturation temperature.

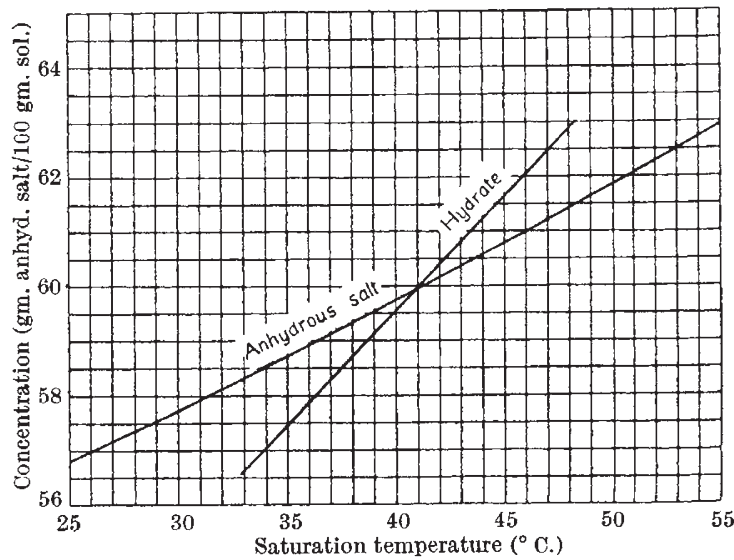

We have used the procedure for obtaining the accompanying solubility curves of ethylenediamine $D$-tartrate and ethylenediamine D-tartrate hydrate. The solutions were prepared from the pure recrystallized anhydrous salt and distilled water only, so that the $p H$ was approximately $6 \cdot 0$. The experimental conditions allowed about thirty points to be obtained in three hours for each curve. Decomposition of the solute in this period is slight, and we believe that our values are not in error by more than $\pm 0 \cdot 1^{\circ} \mathrm{C}$. It was found possible to follow the curves a considerable way into the regions where the solid phases studied are metastable only. To the extent to which they are shown in the graph, the curves are plotted from measured points and are not extrapolated.

It is intended to publish the method and results with more detail elsewhere.

L. A. Dauncey

J. E. STrLLL

Research Laboratories,

The General Electric Co., Ltd., Wembley.

March 8.

${ }^{1}$ Walker, A. C., J. Franklin Inst., 250, 481 (1950).

\section{Complement Fixing Antigen in T5 coli Bacteriophage}

COMPLEMENT fixation with animal viruses has long been known, and Hoyle by the use of the complement fixation reaction has demonstrated a soluble influenza virus antigen which appears in infected cells of the chick embryo prior to the time in the growth-cycle at which infective virus can be found. Up to the present time, so far as I am aware, complement-fixing antibody to the bacterial viruses has not been demonstrated, nor has there been sought in phage. infected cells material analogous to the soluble influenza antigen of Hoyle. However, a conversation with Sir Macfarlane Burnet prompted a search for such substances.

A rabbit serum obtained by immunization with the coli phage 15 contained a high titre of complementfixing antibody. The complement-fixing activity of broth preparations of 75 was related directly to their titre of infective phage, reduction of the phage titre by filtration resulting in a parallel reduction in antigen titre. The phage antigen-antibody system behaved 